\title{
Nitric oxide decreases motility and increases adhesion in human breast cancer cells
}

\author{
M. LAHIRI and J.H.J. MARTIN \\ The Research Institute in Healthcare Science, University of \\ Wolverhampton, Wulfruna Street, Wolverhampton, WV1 1SB, UK
}

Received May 7, 2008; Accepted July 14, 2008

DOI: 10.3892/or_00000218

\begin{abstract}
Our previous results have suggested that increasing aggressiveness of breast tumour cells is associated with the down-regulation of the expression of nitric oxide synthase (NOS). As increasing aggressiveness is associated with a propensity for metastasis, this study aimed to investigate whether our theory applied to the processes of motility and invasion. Although the well-established dual roles of nitric oxide (NO) were evident, most of the results are consistent with our theory. We demonstrated that basal motility is higher in the MCF-7-ADR multidrug-resistant variant cell line compared to the MCF-7 parent cell line and that treatment with NOS inhibitors increased motility in MDA-MB-231 and T47D cells. Exogenous NO was associated with a trend to increase adhesion in the MCF-7 and MDA-MB-231 cell lines. These results are consistent with the theory that loss of NOS expression may be associated with the progression of breast cancers via increase in motility and loss of adhesion.
\end{abstract}

\section{Introduction}

Breast cancer is the most common type of cancer and the second most common cause of cancer deaths in women in the UK. Although $>90 \%$ of women who are newly diagnosed with breast cancer do not have full-blown metastasis to distant organs at the time of diagnosis, subsequent relapse usually results in metastatic spread (1) leading to most patients succumbing to the disease. Therefore, an improvement in understanding the metastatic process is crucial to enable methods that can reduce metastatic disease progression to be developed.

Alterations in the two processes of cell migration and adhesion play a vital role in the metastasis of tumour cells. The metastatic process involves an initial loss of tumour cell-

Correspondence to: Dr J.H.J. Martin, The Research Institute in Healthcare Science, University of Wolverhampton, Wulfruna Street, Wolverhampton, WV1 1SB, UK

E-mail: j.martin@wlv.ac.uk

Key words: breast cancer, nitric oxide, motility, adhesion, metalloproteinase cell adhesion facilitating the dissociation of cancer cells from the primary tumour. Changes in adhesion to the extracellular matrix (ECM) allow the tumour cells to migrate through the tissue and to intravasate into vessels with subsequent transport in the circulation. This is followed by adhesion to endothelial cells with extravasation from the vessels, and migration at the secondary site (2).

There is considerable evidence suggesting that nitric oxide (NO) plays a significant part in almost all stages of cancer including cell migration and adhesion (3). Although several studies have confirmed that NO plays an important role in the two processes (4-6), its function appears to be complex as NO production has been shown to enhance cell migration $(7,8)$ and decrease cell adhesion in some cell types (9) and, conversely, to reduce cell migration (10) and increase cell adhesion in other cell types (11).

The metalloproteinases (MMPs) are a family of enzymes capable of degrading the extracellular matrix. Therefore, the activation of MMPs has an important function in tumour cell migration and invasion (12). Most normal tissues only express very low MMP activity, which is activated in malignant tissue $(13,14)$. One of the possible ways that NO influences tumour cell invasion is by modulating MMP expression $(15,16)$.

This study aimed to investigate the effect of endogenously and exogenously produced NO on cell motility, adhesion and MMP secretion in several human breast cancer cell lines.

\section{Materials and methods}

Detection of cell motility by wound healing assay. Wound healing assays were carried out to detect motility in MCF-7, MCF-7-ADR, T47D and MDA-MB-231 cells. Cells were treated with each of the NOS inhibitors: L-NAME (2 mM); L-NIO $(500 \mu \mathrm{M})$; AMT $(500 \mu \mathrm{M})$; L-arginine $(5 \mathrm{mM})$, with or without L-NAME $(2 \mathrm{mM})$; or SNP $(200 \mu \mathrm{M})$. Cells $\left(2 \times 10^{6}\right)$ were plated out in $35-\mathrm{mm}$ tissue culture dishes and grown until they were $90 \%$ confluent. The cells were treated with various chemicals and left to incubate for $1 \mathrm{~h}$ at $37^{\circ} \mathrm{C}$. Wounds were made on the culture dishes with a pipette tip by a single scratch. The culture dishes were left to incubate for different lengths of time during which the cells bordering the wound began to migrate into the wound. The culture dishes were stained with a solution containing $0.25 \%$ Coomassie blue R-250, 50\% methanol and 10\% acetic acid for 10 min to arrest 

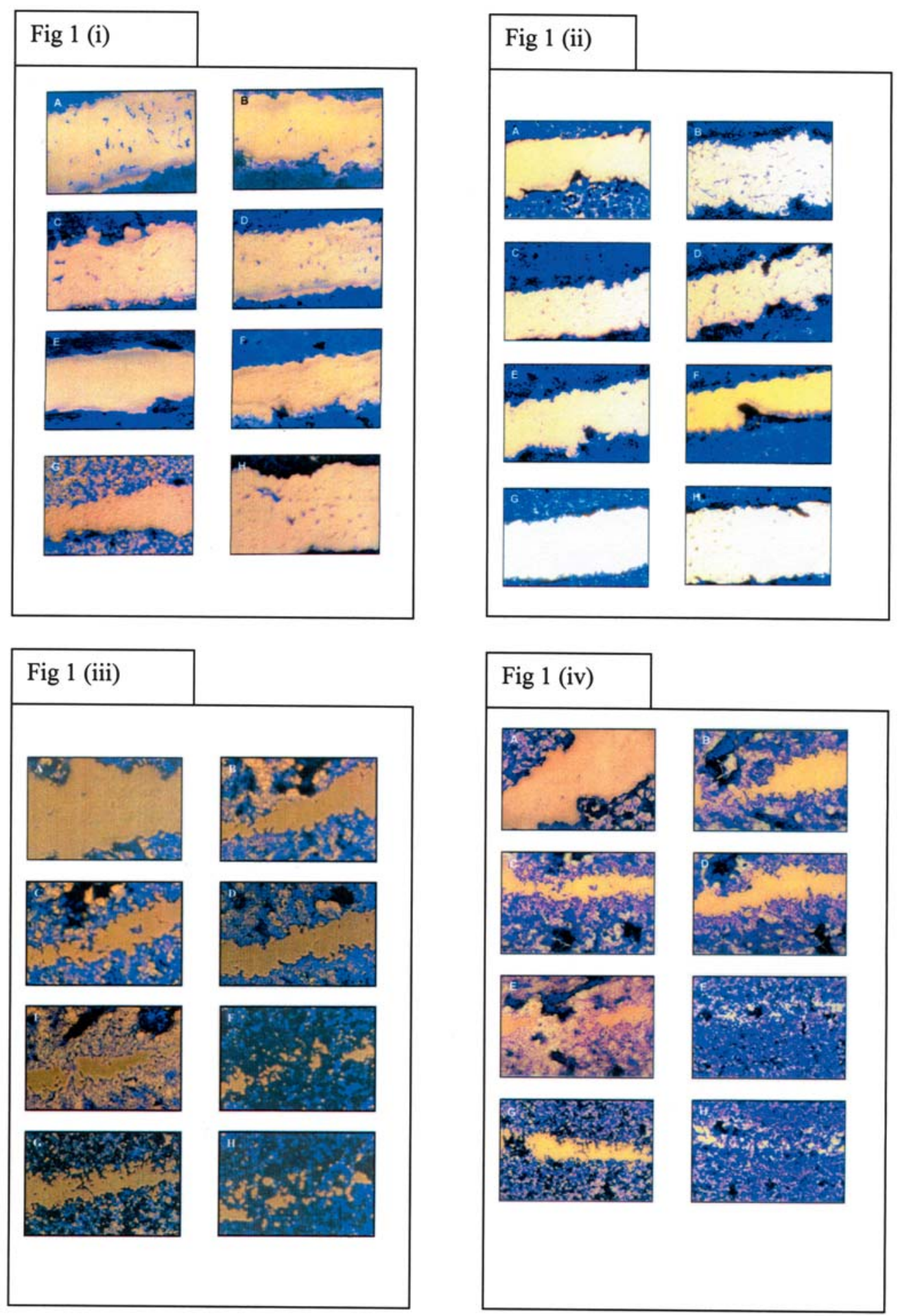

Figure 1. Motility in (i) MCF-7 (ii) MCF-7-ADR (iii) T47D and (iv) MDA-MB-231 cells. Wound healing assay was carried out in treated and untreated MCF-7 cells to detect motility after a time period of $24 \mathrm{~h}$. (A) Initial (just after making the wound), (B) control (after $24 \mathrm{~h}$ ), (C) L-NAME (2 mM), (D) AMT (500 $\mu$ M), (E) L-NIO $(500 \mu \mathrm{M})$, (F) L-arginine (5 mM), (G) L-arginine (5 Mm) + L-NAME (2 mM) and (H) SNP $(200 \mu \mathrm{M})$.

the cells and prevent further migration, and de-stained in distilled water until a clear contrast was obtained. Motility of the cells was determined by the amount of wound closure $(17,18)$.

Detection of matrix metalloproteinases by gelatin zymography. Conditioned media from the four cell lines $\left(1 \times 10^{6}\right)$ were run on SDS-PAGE to assess the pro- and activated forms of MMP-2 and -9 using zymography. Cells $\left(2 \times 10^{6}\right)$ were plated out in 6-well plates. Cells, 80-90\% confluent, were washed with PBS three times and cultured in serum-free medium overnight. Treatments were added to the serum-free media in the wells and incubated for $24 \mathrm{~h}$. The conditioned media were concentrated $~ 50$-fold using Amicon micro-concentrators. The electrolysis equipment was set up using a Mini-Protean ${ }^{\circledR} \mathrm{II}$ electrophoresis cell, and sodium dodecyl sulphate-polyacrylamide gels were prepared with $10 \%$ resolving and $4 \%$ stacking gel. A sample $(20 \mu 1)$ was mixed with sample buffer 


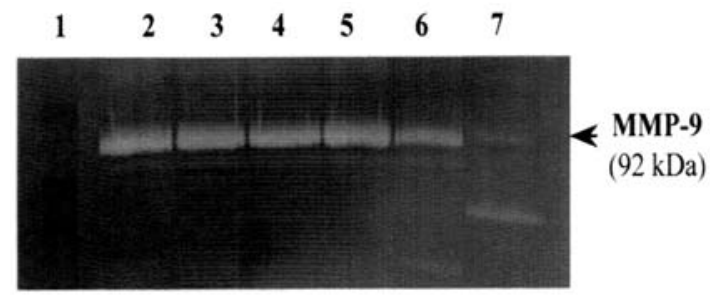

Figure 2. Gelatin zymography analysis of MCF-7-ADR. Conditioned media from treated cells were micro-concentrated, run on electrophoresis gels containing $1 \%$ gelatine, stained with Coomassie brilliant blue and de-stained until a good contrast was obtained. Lane 1, kaleidoscope pre-stained standard; lane 2, MCF-7-ADR untreated; lane 3, MCF-7-ADR + L-NAME (2 mM); lane 4, MCF-7-ADR + L-NIO $(500 \mu \mathrm{m})$; lane 5, MCF-7-ADR + AMT (500 $\mu \mathrm{m})$; lane 6, MMP-9 positive control and lane 7, MMP-2 positive control.

(100 $\mu \mathrm{l}$ ) and placed in a water bath at $55^{\circ} \mathrm{C}$ for $15 \mathrm{~min}$. The sample mixture $(20 \mu \mathrm{l})$ was loaded onto the gels and electrophoresed at 120 volts for $60 \mathrm{~min}$. Gels were washed twice for $30 \mathrm{~min}$ in $2.5 \%(\mathrm{v} / \mathrm{v})$ Triton X-100 to renature the gelatinase activity. The gels were incubated overnight in $1 \mathrm{X}$ low-salt collagenase buffer, stained in $0.1 \%$ Coomassie blue R-250 for $3 \mathrm{~h}$, and destained in $30 \%(\mathrm{v} / \mathrm{v})$ methanol:10\% (v/v) acetic acid, until clear bands were visible on a blue background. The brightness of the bands was analysed on a computer using the Grabber ${ }^{\mathrm{TM}}$ software.

Detection of adhesion. Adhesion assay was carried out using the CyQuant cell proliferation assay kit according to the manufacturer's protocol. Cells $\left(1 \times 10^{5}\right)$ were treated with the various NOS-specific inhibitors, SNP $(200 \mu \mathrm{M})$ or L-arginine $(5 \mathrm{mM})$, and left to incubate on a shaking platform for $30 \mathrm{~min}$ before plating out in duplicate 96 -well tissue culture plates The plates were incubated for different periods of time to allow for adhesion of the cells to the well of the plates. The adhesion process was abrogated when one of the duplicate plates was overturned and patted gently to dislodge any nonadhered cells. The other duplicate plate was centrifuged at $5000 \times \mathrm{g}$ at $4^{\circ} \mathrm{C}$ to give the total cell number. CyQuant dye $(100 \mu 1)$ was added to each of the wells and the plates were read on a Fluroskan Ascent 1.3 fluorescent plate reader. The readings showed the number of cells that had adhered to the wells. A percentage of the number of cells that had adhered to the total number of cells was calculated for each treatment for different time periods (19).

Statistical analysis. Statistical significance was determined using the analysis of variance (ANOVA) followed by Dunnett multiple comparison test and the differences were regarded as significant for values $\mathrm{p}<0.05$.

\section{Results}

Detection of cell motility by wound healing assay. Treatment with NOS inhibitors alone in the MCF-7 and MCF-7-ADR cell lines did not produce any significant changes in motility of the cells [Fig. 1(i)C, (i)D, (i)E and (ii)C, (ii)D, (ii)E]. In the MDA-MB-231 and T47D cell lines, incubation of the cells with the eNOS selective inhibitor, L-NIO [Fig. 1(iii)E and

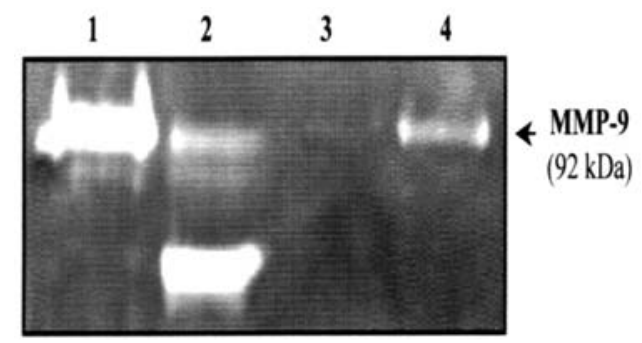

Figure 3. Gelatin zymography analysis of MCF-7-ADR. Conditioned media from treated cells were micro-concentrated, run on electrophoresis gels containing $1 \%$ gelatine, stained with Coomassie brilliant blue and de-stained until a good contrast was obtained. Lane 1, MMP-9 positive control; lane 2, MMP-2 positive control; lane 3, MCF-7-ADR untreated and lane 4, MCF-7$\mathrm{ADR}+\mathrm{SNP}(200 \mu \mathrm{M})$.

(iv)E] produced increased motility compared to the untreated [Fig. 1(iii)B and (iv)B], L-NAME [Fig. 1(iii)C and (iv)C] or AMT-treated [Fig. 1(iii)D and (iv)D] cells.

Although treatment with $5 \mathrm{mM}$ L-arginine did not produce much motility in MCF-7 cells [Fig. 1(i)F] there was a slight increase in motility in the MCF-7-ADR cells [Fig. 1(ii)F]. On treatment of the MDA-MB-231 and T47D cell lines with L-arginine, there was enhanced motility of the cells to close the wound as seen in Fig. 1(iii)F and (iv)F. The increased motility was abrogated in the cell lines by treating L-arginine-induced cells with the general NOS inhibitor, L-NAME [Fig. 1(iii)G and (iv)G].

While treatment of the MCF-7 and MCF-7-ADR cell lines with the NO donor, SNP $(200 \mu \mathrm{M})$, did not stimulate the cells to close the wounds [Fig. 1(i)H and (ii) H], incubation of the MDA-MB-231 and T47D cells with SNP resulted in enhanced motility in the two cell lines [Fig. 1(iii)H and (iv)H].

Detection of matrix metalloproteinases by gelatin zymography. MMP-9 was either not secreted from the MCF-7 and T47D cell lines or was secreted at levels below the detection limit of the assay (data not shown). The MMP-9 pro-form was detected in the conditioned media from incubations of the highly invasive, MDA-MB-231, and the multi-drug resistant, MCF-7-ADR, cell lines. Therefore, only these two cell lines were used in further studies to detect MMP-9 secretion under the influence of various treatments. General (L-NAME) and NOS-selective inhibitors (AMT and L-NIO) were used to detect whether endogenously produced NO had any effect on MMP-9 secretion. It was observed that the NOS-selective inhibitors did not affect MMP-9 secretion levels in MCF-7ADR cells (Fig. 2). Similar results were obtained in the MDAMB-231 cell line (data not shown). A similar zymographic analysis was performed on the MCF-7-ADR and MDA-MB231 cell lines after incubating them overnight with a NO donor, SNP (Fig. 3), to study the effect of exogenously produced NO on MMP-9 secretion. An increase in MMP-9 secretion was observed. The same result was obtained in the MDA-MB-231 cells (data not shown).

Detection of adhesion. In MCF-7, incubating the cells with NOS inhibitors did not produce any significant change in adhesion for any of the time courses compared to the control cells [Fig. 4(i)A]. Incubation of the cells with L-arginine also 


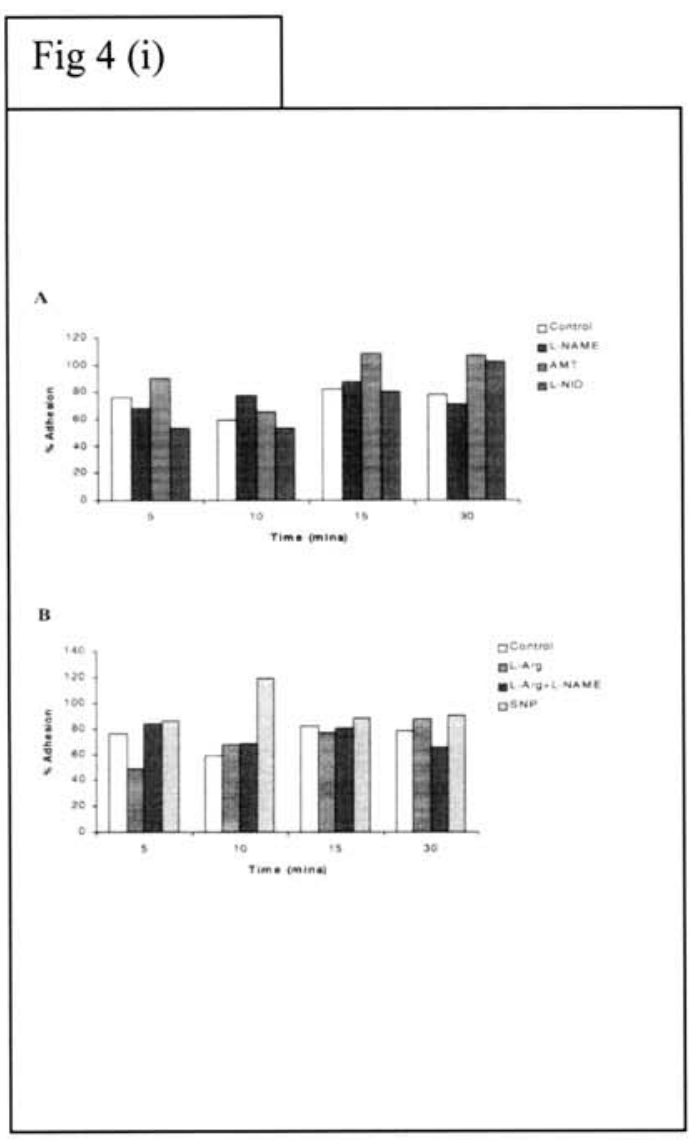

Fig 4 (ii)

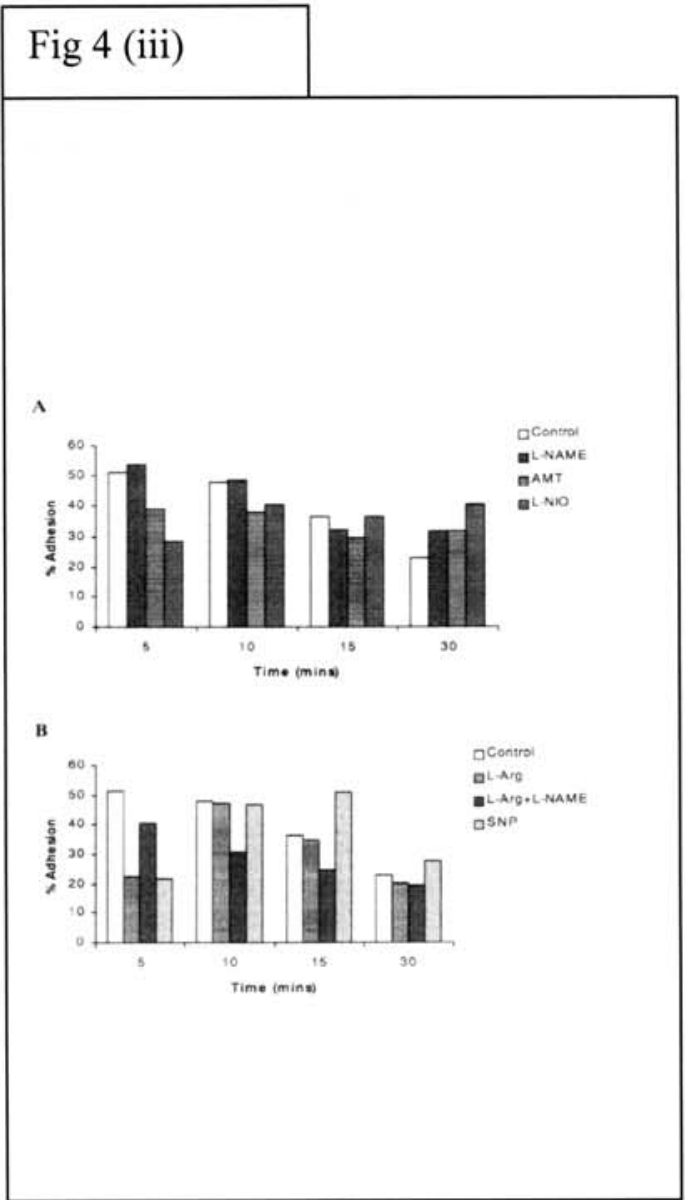

Fig 4 (iv)

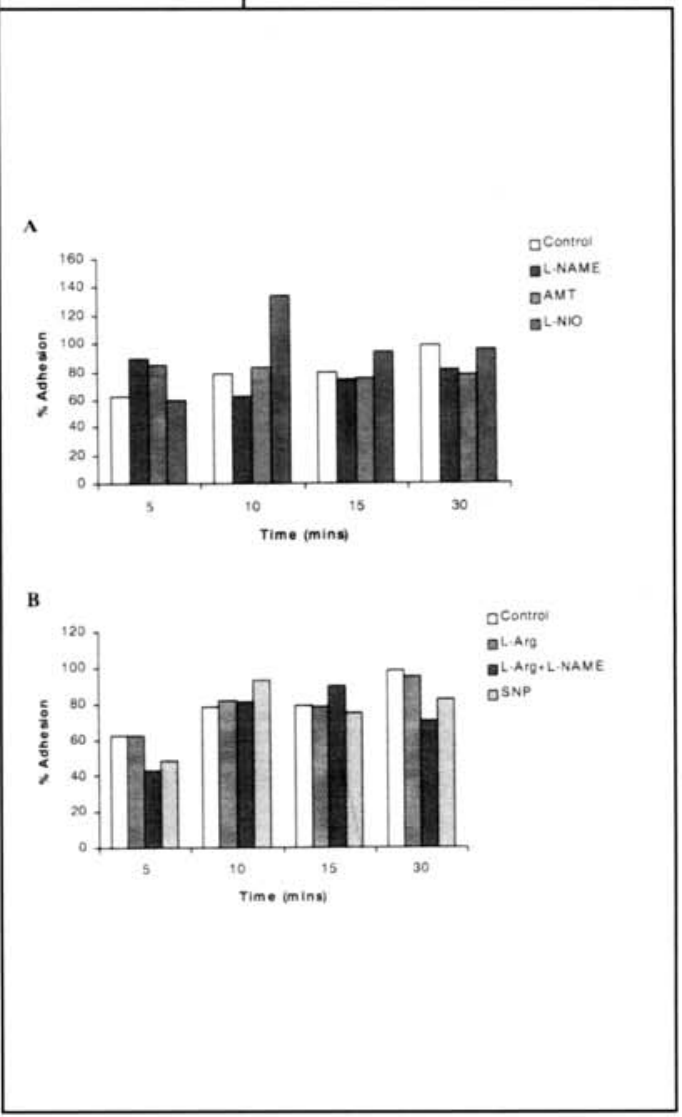

Figure 4. Adhesion in (i) MCF-7 (ii) MCF-7 ADR (iii) T47D and (iv) MDA-MB-231 cells. Adhesion assay was performed on cells after incubating for 30 min (A) with and without the inhibitors of L-NAME $(2 \mathrm{mM})$, AMT $(500 \mu \mathrm{m})$, L-NIO $(500 \mu \mathrm{m})$ and (B) with and without L-arginine $(5 \mathrm{mM})$, L-NAME $(2 \mathrm{mM})$ or SNP $(200 \mu \mathrm{m})$. 
did not produce any significant effect in the adhesion, but the addition of L-NAME to the L-arginine-treated cells produced a significant decrease $(\mathrm{p}<0.05)$ in adhesion $(66 \%, \mathrm{p}<0.02)$ at the 30-min time period compared to the L-arginine-stimulated cells $(88 \%)$, as shown in Fig. 4(i)B. Treatment of the cells with the NO donor, SNP, showed an enhanced adhesion for the time points and achieved significance at the 10-min incubation period $(119 \%, \mathrm{p}<0.05)$ compared to the control $(59 \%)$.

A similar trend was observed in the MCF-7-ADR cell line. NOS inhibitors [Fig. 4(ii)A] and L-arginine [Fig. 4(ii)B] failed to produce any significant effect on adhesion in the MCF-7-ADR cells. However, the addition of L-NAME to the L-arginine-treated cells resulted in a significant decrease in adhesion at the 5 -min incubation time $(66 \%$ for L-arginine only, compared to $32 \%$ for L-arginine plus L-NAME, $\mathrm{p}<0.05$ ) and 30-min time period (83\% for L-arginine only, compared to $35 \%$ for L-arginine plus L-NAME, $\mathrm{p}<0.05$ ). Incubation of the MCF-7-ADR cells with SNP failed to produce any significant effect on adhesion for any of the time periods.

In the MDA-MB-231 cells treated with L-NIO, a significant decrease in adhesion was observed at the $5-\min (28 \%, \mathrm{p}<0.05)$ time period compared to the control (51\%), Fig. 4(iii)A. Treating the cells with L-arginine showed a decrease in adhesion for the time periods as shown in Fig. 4(iii)B with the decrease being statistically significant at the 5-min time period $(23 \%, \mathrm{p}<0.05)$ compared to the control $(51 \%)$. The addition of L-NAME to the L-arginine-stimulated cells failed to produce any significant effect on adhesion. When cells were treated with the NO donor, SNP, there was an increase in adhesion at the 15- and 30-min time points which achieved significance at $15 \mathrm{~min}(50 \%, \mathrm{p}<0.05)$ compared to the control $(35 \%)$.

In the T47D cell treatment with AMT, a significant increase in adhesion at the 5 -min $(85 \%, \mathrm{p}<0.05)$ time period compared to the control (63\%) was produced, as can be seen in Fig. 4(iv)A. Treatment with L-arginine did not affect cell adhesion. Similarly, adding L-NAME to the L-argininestimulated cells failed to produce any significant effect on adhesion. Exogenously produced NO, produced by the NO donor, SNP, showed a significant decrease in the percentage of adhesion $(49 \%, \mathrm{p}<0.05)$ at the 5 -min time period compared to the control $(63 \%)$.

\section{Discussion}

Cell migration is a key aspect of tumour metastasis and although NO is thought to play an important role in this process, its precise function in cell motility has yet to be properly defined. We have previously demonstrated a reduced expression of iNOS and eNOS in estrogen-independent (20) and multidrug-resistant (21) human breast cancer cell lines. Furthermore, we have shown a negative correlation between eNOS expression and histological grade, and a positive correlation between eNOS and estrogen receptor expression in primary invasive ductal breast carcinoma (22). Taken together these results indicate a down-regulation of the expression of NOS with increasing aggressiveness of the tumour. In general, the increasing aggressiveness of a tumour tends to be associated with a propensity for increased motility leading to increased metastatic capability.
Our current results are consistent with loss of the NOS expression being associated with increased motility. We demonstrated basal motility in the multi-drug resistant MCF-7ADR cell line to be greater than that in the MCF-7 parent cell line, consistent with a reduced NOS expression in the variant cell line. We also showed basal motility to be greater in the more aggressive MDA-MB-231 cell line, again consistent with a reduced NOS expression. We suggest that a constant production of NO in the less aggressive human breast cancer cell lines leads to suppression of their motility. This possibly occurs through a similar mechanism to that which has been demonstrated with neutrophils, where NO derived from human umbilical vein endothelial cells was shown to act on neutrophils to inhibit transendothelial migration via the activation of soluble guanylyl cyclise (23). Similarly, up-regulation of the iNOS gene has been shown to inhibit migration of the B88t oral cancer cell line (24). Furthermore, in MDA-MB-231 and T47D cells, reduction of the NO level by adding the L-NIO inhibitor caused an increase in motility, again supporting the theory that a reduced NO production is associated with increasing motility.

Interestingly, in all of the cell lines, L-arginine caused an increase in motility. Although this does not fit neatly with our theory, it is well established that NO has a controversial role to play in cancer cell biology. The well-established difficulty in markedly unravelling the apparently opposing roles of NO has been eloquently described by others who have referred to NO as having a 'dual personality' (25), being 'two sides of the same coin' (26) and a biological double-faced Janus (27). In keeping with its dual role, NO has been shown to be involved in enhancing cell migration through the modification of actin (28) and to have an inhibitory effect on cellular migration via the dissociation of actin stress fibres (29).

The biphasic responses of tumour cells to NO appear to be due to several factors including NO concentration, length of exposure, and NO-induced redox flux (30). The results herein are yet another example of the biphasic nature of NO in cancer cell biology where a low basal level of NO production is capable of suppressing cell motility but when higher concentrations of NO are generated either endogenously with L-arginine or exogenously with SNP it leads to enhanced cell motility.

Since the motility of tumour cells can only occur after the extracellular matrix (ECM) is proteolysed, we investigated whether NO played a role in MMP secretion. It was observed that although endogenously produced NO did not affect MMP-9 secretion, exogenously produced NO was able to cause an increase in MMP-9 secretion in MCF-7-ADR and MDA-MB-231 human breast cancer cell lines. This is consistent with enhanced motility in MDA-MB-231 cells with the addition of SNP.

Several studies concur with our findings. NO produced after cytokine stimulation has been shown to increase MMP-2 activity in cultured rat mesangial cells with a further increase in production following co-incubation with L-arginine (31). In a murine mammary adenocarcinoma cell line, it was demonstrated that enhanced NO production by stimulation of the cells by IFN- $\gamma$ and LPS led to an up-regulation of MMP- 2 and a down-regulation of TIMP-2 and -3 levels (32). High levels 
of NO led to an increased production of MMP-2 and -9 in rabbit articular chondrocytes (33) and the addition of a NOS inhibitor to IL-1ß-stimulated chondrocytes reduced MMP activation, suggesting that $\mathrm{NO}$ plays a role in cytokine-induced MMP activation in the cells (34).

In our study NOS inhibitors had no effect on MMP-9 secretion in MCF-7-ADR or MDA-MB-231 human breast cancer cells, as demonstrated by other studies. When human cervical explants and fibroblasts were treated with a NO donor, in vivo and in vitro, it was observed that exogenously added NO had no effect on the secretion of MMP-2 and -9 (35).

Throughout the literature the conflicting, contrasting and apparently contradictory results of investigations into the roles of NO in tumour biology have been continually highlighted $(26,36,37)$. The effect on MMP expression is no exception. In contrast to the previous studies that have agreed with our current findings in suggesting a role for exogenous NO in increasing MMP secretion, there are equally valid studies suggesting that NO has an inhibitory role on MMP secretion, again highlighting the dual action of NO in tumour cell biology.

It has been observed that when a NO donor was used in conjunction with a cytokine, the NO donor exhibited a strong inhibitory effect on the MMP-9 mRNA level (38). In another study, in rat mesangial cells it was shown that the addition of a NOS inhibitor dose-dependently increased the steady-state mRNA levels of cytokine-induced MMP-9, suggesting that endogenously produced NO exerted a tonic inhibition of MMP-9 expression (39). Rat-aortic smooth muscle cells were transfected with the eNOS gene and on studying the gelatinolytic activity it was observed that there was a decrease in MMP-2 and -9 activity (40).

Our current results are consistent with NOS expression being associated with increased adhesiveness. We demonstrated basal adhesiveness in the multidrug-resistant variant MCF-7-ADR breast cancer cells to be lower than in the parent cell line MCF-7, and this is consistent with a reduced NOS expression in the variant cell line. We also showed basal adhesiveness to be reduced in the more aggressive MDAMB-231 cell line, again consistent with a reduced NOS expression and an increased tumour aggressiveness.

There is a growing body of evidence suggesting that NO is a naturally occurring anti-adhesive molecule as seen in studies where NO is capable of inhibiting platelet aggregation (41) and adhesion to the vascular endothelium (42) and subendothelial matrix (43). Similarly, endogenously and exogenously produced NO are able to attenuate tumour cell adhesion to postcapillary venules (44) and fibronectin (45).

However, in keeping with its dual role, there is evidence suggesting that NO increases adhesion via mechanisms involving protein kinase G-mediated P-selectin mobilization and PAF synthesis (46). In the present study, our results may favour this role for NO in adhesion as the SNP treatment exhibited a trend to increase adhesion in the MCF-7 and MDA-MB-231 cell lines but not in T47D.

In conclusion, nitric oxide plays an important role in cancer cell biology especially during the metastatic process. As with most of its other functions, its role in motility and adhesion is subject to the same inconsistencies. We have shown that NO decreases motility and increases adhesion in some human breast cancer cells. However, further investigation is necessary to resolve the complexities before clinical advances can be implemented.

\section{References}

1. Baum M and Badwe RA: Does surgery influence the natural history of breast cancer? In: Breast Cancer: Controversies in Management. Wise H and Johnson HJ (eds). Futura, Armonk, NY, pp61-69, 1994.

2. Pass HI: Biology of metastatic disease. Semin Thorac Cardiovasc Surg 14: 10-17, 2002.

3. Williams EL and Djamgoz MB: Nitric oxide and metastatic cell behaviour. Bioessays 27: 1228-1238, 2005

4. Goligorsky MS, Budzikowski AS, Tsukahara H and Noiri E: Co-operation between endothelin and nitric oxide in promoting endothelial cell migration and angiogenesis. Clin Exp Pharmacol Physiol 26: 269-271, 1999.

5. Goligorsky MS, Noiri E, Peresleni T and Hu Y: Role of nitric oxide in cell adhesion and locomotion. Exp Nephrol 4: 314-321, 1996.

6. Noiri E, Peresleni T, Srivastava N, et al: Nitric oxide is necessary for a switch from stationary to locomoting phenotype in epithelial cells. Am J Physiol 270: C794-C802, 1996.

7. Jadeski LC, Hum KO, Chakraborty C and Lala PK: Nitric oxide promotes murine mammary tumour growth and metastasis by stimulating tumour cell migration, invasiveness and angiogenesis. Int J Cancer 86: 30-39, 2000.

8. Jadeski LC, Chakraborty C and Lala PK: Nitric oxide-mediated promotion of mammary tumour cell migration requires sequential activation of nitric oxide synthase, guanylate cyclise and mitogenactivated protein kinase. Int J Cancer 106: 496-504, 2003.

9. Sun Y, Liu J, Oian F and Xu Q: Nitric oxide inhibits T cell adhesion and migration by down-regulation of beta 1-integrin expression in immunologically liver-injured mice. Int Immunopharmacol 6: 616-626, 2006.

10. DalSecco D, Moreira AP, Freitas A, et al: Nitric oxide inhibits neutrophil migration by a mechanism dependent on ICAM-1: role of soluble guanylate cyclise. Nitric Oxide 1: 77-86, 2006.

11. Guo H, Marroquin CE, Wai PY and Kuo PC: Nitric oxidedependent osteopontin expression induces metastatic behaviour in HepG2 cells. Dig Dis Sci 50: 1288-1298, 2005.

12. Jodele S, Blavier L, Yoon JM and DeClerck YA: Modifying the soil to affect the seed: role of stromal-derived matrix metalloproteinases in cancer progression. Cancer Metastasis Rev 25: 35-43, 2006.

13. Bjornland K, Flatmark K, Pettersen S, Aaasen AO, Fodstad O and Maelandsmo GM: Matrix metalloproteinases participate in osteosarcoma invasion. J Surg Res 127: 151-156, 2005.

14. Zhang A, Meng L, Wang Q, et al: Enhanced in vitro invasiveness of ovarian cancer cells through up-regulation of VEGF and induction of MMP-2. Oncol Rep 15: 831-836, 2006.

15. Upchurch GR, Ford JW, Weiss SJ, et al: Nitric oxide inhibition increases matrix metalloproteinase- 9 expression by rat aortic smooth muscle cells in vitro. J Vasc Surg 34: 76-83, 2001.

16. Yoshida M, Sagawa N, Itoh H, et al: Nitric oxide increases matrix metalloproteinase-1 production in human uterine cervical fibroblast cells. Mol Hum Reprod 7: 979-985, 2001.

17. Fincham VJ and Frame MC: The catalytic activity of Src is dispensable for translocation to focal adhesions but controls the turnover of these structures during cell motility. EMBO J 17: 81-92, 1998.

18. Nobes CD and Hall A: Rho GTPases control polarity, protrusion, and adhesion during cell movement. J Cell Biol 144: 1235-1244, 1999.

19. Schultz RM, Silberman S, Persky B, Bajkowski AS and Carmichael DF: Inhibition by human recombinant tissue inhibitor of metalloproteinases of human amnion invasion and lung colonization by murine B16-F10 melanoma cells. Cancer Res 48: 5539-5545, 1988.

20. Martin JHJ, Alalami O and van den Berg HW: Reduced expression of endothelial and inducible nitric oxide synthase in a human breast cancer cell line which has acquired estrogen independence. Cancer Lett 144: 65-74, 1999.

21. Lahiri M and Martin JHJ: Reduced expression of endothelial and inducible nitric oxide synthase in a multi-drug resistant variant of the MCF-7 human breast cancer cell line. Oncol Rep 12: $1007-1011,2004$ 
22. Martin JHJ, Begum S, Alalami O, Harrison A and Scott K: Endothelial nitric oxide synthase: correlation with histologic grade, lymph node status and estrogen receptor expression in human breast cancer. Tumor Biol 21: 90-97, 2000.

23. Oka S, Sasada M, Yamamoto K, et al: Nitric oxide derived from human umbilical vein endothelial cells inhibits transendothelial migration of neutrophils. Int J Hematol 81: 220-227, 2005.

24. Harada K, Supriatno K, Kawaguchi S, Tomitaro O, Yoshida H and Sato M: Overexpression of iNOS gene suppresses the tumorigenicity and metastasis of oral cancer cells. In Vivo 18: 449-455, 2004

25. Colasanti M and Suzuki H: The dual personality of NO. Trends Pharmacol Sci 21: 249-252, 2000.

26. Lechne M, Lirk P and Rieder J: Inducible nitric oxide synthase (iNOS) in tumour biology: two sides of the same coin. Semin Cancer Biol 15: 277-289, 2005.

27. Thippeswamy T, McKay JS, Quinn JP and Morris R: Nitric oxide, a biological double-faced janus - is this good or bad? Histol Histopathol 21: 445-458, 2006.

28. Jun CD, Han MK, Kim UH and Chung HT: Nitric oxide induces ADP-ribosylation of actin in murine macrophages: association with the inhibition of pseudopodia formation, phagocytic activity, and adherence on a laminin substratum. Cell Immunol 174: 25-34, 1996.

29. Hassid A, Yao J and Huang S: NO alters cell shape and motility in aortic smooth muscle cells via protein tyrosine phosphatase 1B activation. Am J Physiol 277: H1014-H1026, 1999.

30. Ridnour LA, Thomas DD, Donzelli S, et al: The biphasic nature of nitric oxide responses in tumour biology. Antioxid Redox Signal 8: 1329-1337, 2006.

31. Trachtman H, Futterweit S, Garg SP, Reddy K and Singhal PC: Nitric oxide stimulates the activity of a $72-\mathrm{kDa}$ neutral matrix metalloproteinase in cultured rat mesangial cells. Biochem Biophys Res Commun 218: 704-708, 1996.

32. Orucevic A, Bechberger J and Green AM: Nitric-oxide production by murine mammary adenocarcinoma cells promotes tumor-cell invasiveness. Int J Cancer 81: 889-896, 1999.

33. Sasaki K, Hattori T, Fujisawa T, Takahashi K, Inoue $H$ and Takigawa M: Nitric oxide mediates interleukin-1-induced gene expression of matrix metalloproteinases and basic fibroblast growth factor in cultured rabbit articular chondrocytes. J Biochem 123: 431-439, 1998.

34. Tamura T, Nakanishi T, Kimura Y, et al: Nitric oxide mediates interleukin-1-induced matrix degradation and basic fibroblas growth factor release in cultured rabbit articular chondrocytes: a possible mechanism of pathological neovascularization in arthritis. Endocrinology 137: 3729-3737, 1996.
35. Ledingham MA, Denison FC, Riley SC and Norman JE: Matrix metalloproteinases- 2 and -9 and their inhibitors are produced by the human uterine cervix but their secretion is not regulated by nitric oxide donors. Hum Reprod 14: 2089-2096, 1999.

36. Brennan PA and Moncada S: From pollutant gas to biological messenger: the diverse actions of nitric oxide in cancer. Am R Coll Surg Engl 84: 75-78, 2002.

37. Wink DA, Vodovotz Y, Laval J, Laval F, Dewhirst MW and Mitchell JB: The multifaceted roles of nitric oxide in cancer. Carcinogenesis 19: 711-721, 1998.

38. Eberhardt W, Beeg T, Beck KF, et al: Nitric oxide modulates expression of matrix metalloproteinase-9 in rat mesangial cells. Kidney Int 57: 59-69, 2000.

39. Eberhardt W, Akool S, Rebhan J, et al: Inhibition of cytokineinduced matrix metalloproteinase 9 expression by peroxisome proliferator-activated receptor alpha agonists is indirect and due to a NO-mediated reduction of mRNA stability. J Biol Chem 277: 33518-33528, 2002.

40. Gurjar MV, Sharma RV and Bhalla RC: eNOS gene transfer inhibits smooth muscle cell migration and MMP-2 and MMP-9 activity. Arterioscler Thromb Vasc Biol 19: 2871-2877, 1999.

41. Ramomski MW, Palmer RM and Moncada S: Comparative pharmacology of endothelium-derived relaxing factor, nitric oxide and prostacyclin in platelets. Br J Pharmacol 92: 181-187, 1987.

42. Ramomski MW, Palmer RM and Moncada S: Endogenous nitric oxide inhibits human platelet adhesion to vascular endothelium. Lancet 2: 1057-1058, 1987.

43. de Graff JC, Banga JD, Moncada S, Palmer RM, Groot PG and Sixma JJ: Nitric oxide functions as an inhibitor of platelet adhesion under flow conditions. Circulation 85: 2284-2290, 1992.

44. Kong L, Dunn GD, Keefer LK and Korthuis RJ: Nitric oxide reduces tumor cell adhesion to isolated rat postcapillary venules. Clin Exp Metastasis 14: 335-343, 1996.

45. Ivanova K, Poole IC, Gerzar R, Westerhof W and Das PK: Effect of nitric oxide on the adhesion of human melanocytes to extracellular matrix components. J Pathol 183: 469-476, 1997.

46. Okayama N, Coe L, Itoh M and Alexander J: Exogenous nitric oxide increases neutrophil adhesion to cultured human endothelial monolayers through a protein kinase $\mathrm{G}$ dependent mechanism. Inflammation 23: 37-50, 1999. 